\title{
Health-related quality of life among Ebola survivors in Sierra Leone: the role of socio-demographic, health-related and psycho-social factors
}

Peter Bai James ${ }^{1,2^{*}}$ (D) Jon Wardle ${ }^{1,4}$, Razak M. Gyasi ${ }^{3}$, Amie Steel ${ }^{4}$, Jon Adams ${ }^{4}$, John Alimamy Kabba ${ }^{5}$, Abdulai Jawo Bah ${ }^{2,6,7}$, Michael Lahai ${ }^{2}$ and Eugene B. Conteh ${ }^{2}$

\begin{abstract}
Background: Evidence of how social factors affect the health-related quality of life (HRQoL) of Ebola virus disease (EVD) survivors is limited. Our study explores the association between socio-demographic, health-related and psychosocial (stigma) factors and EVD survivors'health-related quality of life (HRQoL) in Sierra Leone.

Methods: We conducted a nationwide cross-sectional study among 358 EVD survivors between January and August 2018. We used a multistage sampling method to recruit EVD survivors, and the RAND 36-Item Health Survey item was used to assess the HRQoL. Data were analysed using descriptive statistics and multiple linear regression.

Results: When comparing by each dimension in relation to their respective summary scores, role limitation physical $[0.00(50.00)]$ and role limitation emotional $[0.00$ (33.33)] were the most affected physical health and mental health domains among EVD survivors respectively. EVD survivors who were older $(\beta=-3.90,95 \% \mathrm{Cl}-6.47$ to -1.32 , $p=0.003$ ), had no formal education ( $\beta=-2.80,95 \% \mathrm{Cl}-5.16$ to $-0.43, p=0.021)$, experienced a unit increase in the number of post-Ebola symptoms $(\beta=-1.08,95 \% \mathrm{Cl}-1.74$ to $-0.43, p<0.001)$ and experienced a unit increase in enacted stigma ( $\beta=-2.61,95 \% \mathrm{Cl}-4.02$ to $-1.20, p<0.001$ ) were more likely to report a decreased level of physical health. EVD survivors who experienced a unit increase in the time spent in the Ebola treatment centre $(\beta=-0.60$, $95 \% \mathrm{Cl}-0.103$ to $-0.18, p=0.006$ ) and those who experienced a unit increase in enacted Stigma were more likely to report decreased levels of mental health $(\beta=-1.50,95 \% \mathrm{Cl}-2.67$ to $-0.33, p=0.012)$.

Conclusion: Sociodemographic, health-related, and psycho-social factors were significantly associated with decrease levels of HRQOL. Our findings improve our understanding of the factors that might influence the HRQoL and suggest the need for EVD survivors to be provided with a comprehensive healthcare package that caters for their physical and mental health needs.
\end{abstract}

Keywords: Ebola, Ebola survivors, Health-related quality of life, SF-36, Physical heath, Mental health, Sierra Leone

*Correspondence: jamepeb@yahoo.com

2 Faculty of Pharmaceutical Sciences, College of Medicine and Allied Health Sciences, University of Sierra Leone, Freetown, Sierra Leone

Full list of author information is available at the end of the article

\section{Background}

The Ebola virus disease (EVD) is a haemorrhagic fever that is considered an emerging infectious disease with high morbidity and mortality [1]. Although recent outbreaks have occurred in East Africa [2, 3], the 2013-2016 EVD epidemic in West Africa was unprecedented, with original author(s) and the source, provide a link to the Creative Commons licence, and indicate if changes were made. The images or other third party material in this article are included in the article's Creative Commons licence, unless indicated otherwise in a credit line to the material. If material is not included in the article's Creative Commons licence and your intended use is not permitted by statutory regulation or exceeds the permitted use, you will need to obtain permission directly from the copyright holder. To view a copy of this licence, visit http://creativecommons.org/licenses/by/4.0/. The Creative Commons Public Domain Dedication waiver (http://creativeco mmons.org/publicdomain/zero/1.0/) applies to the data made available in this article, unless otherwise stated in a credit line to the data. 
28,616 and 11,310 people estimated to have been infected and died respectively [4]. Despite the high morbidity and mortality of EVD, more than 10,000 patients survived EVD, and majority of the survivors suffering from physical and mental complications [5-7]. Sierra Leone was one of the most affected countries during the 2013-2016 EVD outbreak and is home to approximately 4000 survivors [8]. In addition, several Sierra Leonean studies have reported a considerable number of EVD survivors who continue to grapple with the Ebola-related physical disabilities and psychopathologies 3-4 years post-discharge from an Ebola treatment centre (ETC). Such disabilities and psychopathologies are believed to have had untoward effects on their overall quality of life [9-12].

It is important to evaluate both objective (e.g., biochemical and clinical assessment) and subjective (e.g., patient-reported health-related quality of life [HRQoL]) measures of the impact of EVD on survivors' health and well-being. HRQoL instruments evaluate a patient's own assessment of their level of functioning and satisfaction with their health and psycho-social well-being [13]. They measure individual's physical, mental, emotional, and social functioning. Through self-appraisal, HRQoL measures also discern dysfunction and disability associated with diseases, injuries, and health behaviours at an individual and community level. HRQoL [13] has been employed to evaluate the health and psycho-social wellbeing of survivors of emerging and re-emerging infectious diseases [14-16]. For instance, a cross-sectional study of Middle East Respiratory Syndrome (MERS) survivors with critical illness were found to have a reduced quality of life than their counterparts with less severe illness [17]. Similarly, low HRQoL was found post-discharge among patients who had severe acute respiratory syndrome (SARS) [18] and COVID-19 [19]. As for other emerging and re-emerging infectious diseases, EVD survivors' socio-demographic, behavioural, health and psychosocial-related factors may also affect their HRQoL. For example, HRQoL was lower among MERS survivors who had a severe form of the disease [17]. Also, among COVID-19 survivors, being female and obese were associated with low mental health and physical health component of HRQOL, respectively [19]. A recent study among COVID-19 survivors in Finland found that age, sex, occupation, number of comorbidities, acute respiratory distress syndrome severity, duration of invasive mechanical ventilation were predictors of HRQoL 90 days following discharge from an intensive care unit [20].

Post-Ebola sequelae have placed limitations on survivors' ability to function in society. For instance, loss of sight, hearing and experiences of chronic pain can all lead to the inability to perform daily life activities, such as walking and running. In some cases, such physical limitations have led to survivors being unemployed, leading to dependence on others and a loss of self-worth particularly among those with advanced age $[6,21,22]$. While studies have explored the post-Ebola physical and mental health sequelae among survivors $[6,7,9,23]$, data are lacking on the impact of EVD on the overall HRQoL of survivors. Also, the current interim guideline on the management of post-Ebola sequelae among survivors is devoid of any specific reference to HRQoL due to EVD [24]. Based on studies in survivors of other emerging and re-emerging infectious disease outbreaks $[17,19,20$, 25], we hypothesised that socio-demographic, healthrelated and psycho-social (Ebola-related stigma) factors would influence HRQoL among EVD survivors. Therefore, this study explores the association between sociodemographic, health-related and psycho-social (stigma) factors and EVD survivors' health-related quality of life (HRQoL) in Sierra Leone.

\section{Methods}

\section{Health-related quality of life theoretical framework}

The theoretical framework underpinning our study is based on the revised Wilson and Cleary's HRQoL model by Ferrans et al. [26], in which they added individual and environmental characteristics to the commonly known Wilson and Cleary model [27]. We adapted the revised model by Ferrans et al. [26]. In our adapted model, sociodemographic features such as age, sex, marital status, financial status were considered to be representing the individual characteristics in the model. Health-related factors such as post-Ebola symptoms and duration of stay at the Ebola treatment centre were considered under symptoms and functional status. Also, location and stigma were considered part of environmental characteristics, whereas general health was considered under general health perceptions. The adapted model is shown in Fig. 1.

\section{Study design, setting, population, and sampling}

We conducted a nationwide cross-sectional study between January and August 2018. We conducted our study across five districts of the four administrative regions (Western Area, Northern Province, Eastern Province and Southern Province) of Sierra Leone. The locations of the five districts are shown in Fig. 2. The five districts include western area urban and western area rural districts (both in the Western area), Bo District (Southern Province), Kenema district (Eastern Province) and Bombali District (Northern Province). We chose these districts due to the high number of confirmed EVD cases reported during the outbreak, and they were host to the highest number of EVD survivors in all geographic regions in Sierra Leone [28]. 


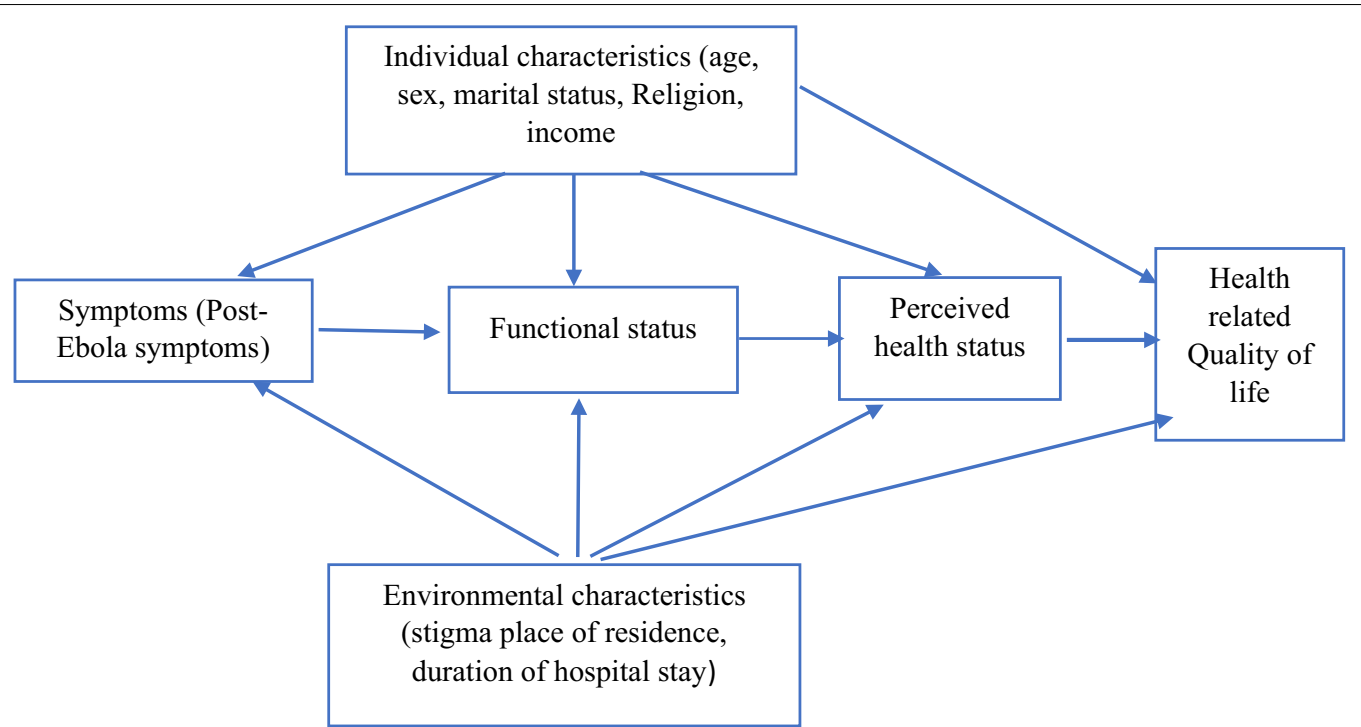

Fig. 1 Theoretical framework underpinning how our independent variables influence Health-related Quality of life

We recruited adult EVD survivors 18 years or over who reported suffering from one or more post-Ebola symptoms. We excluded EVD survivors who could not provide information due to certain health and psychological limitations, such as memory loss, hearing loss, high fever and bleeding or emotional distress. A sample size formula for cross-sectional studies $\left(\mathrm{N}=\mathrm{z}^{2} \mathrm{pq} / \mathrm{d}^{2}\right)$ was employed to determine the required sample size for our study, given that this study is part of an overall study that focussed on determining the prevalence of the post-Ebola symptoms among Ebola survivors. A minimum sample of 351 EVD survivors was required. However, we recruited 400 EVD survivors to allow for non-responses. We used multistage sampling to recruit EVD survivors across Sierra Leone. First, we divided the country into four geographical regions, i.e. the northern, south, east, and western regions. Secondly, we purposively chose five districts to cover all four regions. Our selection of these five districts was informed by the total number of confirmed EVD cases, and these districts had the highest number of EVD survivors. Then, we purposively chose the headquarter town or the central city as our urban area in each of the selected districts and used a lottery method to randomly choose a rural area from the list of rural settlements around the chosen urban area. In the final stage, we used simple random sampling through the lottery method to select EVD survivors. The number of EVD survivors sampled in each district was based on proportional representation using the national list of registered EVD survivors. We obtained the list from the Sierra Leone Association of Ebola survivors (SLAES). We invited 400 EVD survivors from Bombali District (Northern Region) $(n=137)$,
Bo District (Southern Region) ( $\mathrm{n}=62)$, Kenema District (Eastern Region) $(\mathrm{n}=70)$ and Western area urban and Western area rural districts (Western Region) $(n=131)$. Of those invited to participate, 377 consented to participate in the study.

\section{Measures}

Demographics and health-related characteristics

We collected data on EVD survivors' age group (18-33, $34-49$ and $\geq 50$ years), sex (male vs. female), marital status (single, married, separated/divorce and widowed), educational status (non-formal, primary, secondary and tertiary), religious affiliation (Christianity, Islam), employment status, financial status (difficult all the time, difficult sometimes, not too bad and easy), region (north, south, east and wester), place of residence (urban and rural), known chronic condition(s) before Ebola (Yes or No), current perceived health status (very good, good, fair and poor), duration (years) since discharged from ETC, time (days) spent at ETC, number of post-Ebola symptoms, types of post-Ebola symptoms (joint pain, headache, ocular symptoms, fatigue, back pain, abdominal pain, auditory symptoms, skin disorders and alopecia). The inclusion of health-related variables was based on the available literature [7].

\section{Psycho-social characteristics (Ebola-related stigma)}

Ebola-related stigma was assessed using an adapted 33-item validated HIV-related stigma for people living with HIV/AIDS (HASI-P) instrument [29], given that no validated Ebola-related stigma instrument exists. The HASI-P instrument has been validated among HIV/ 


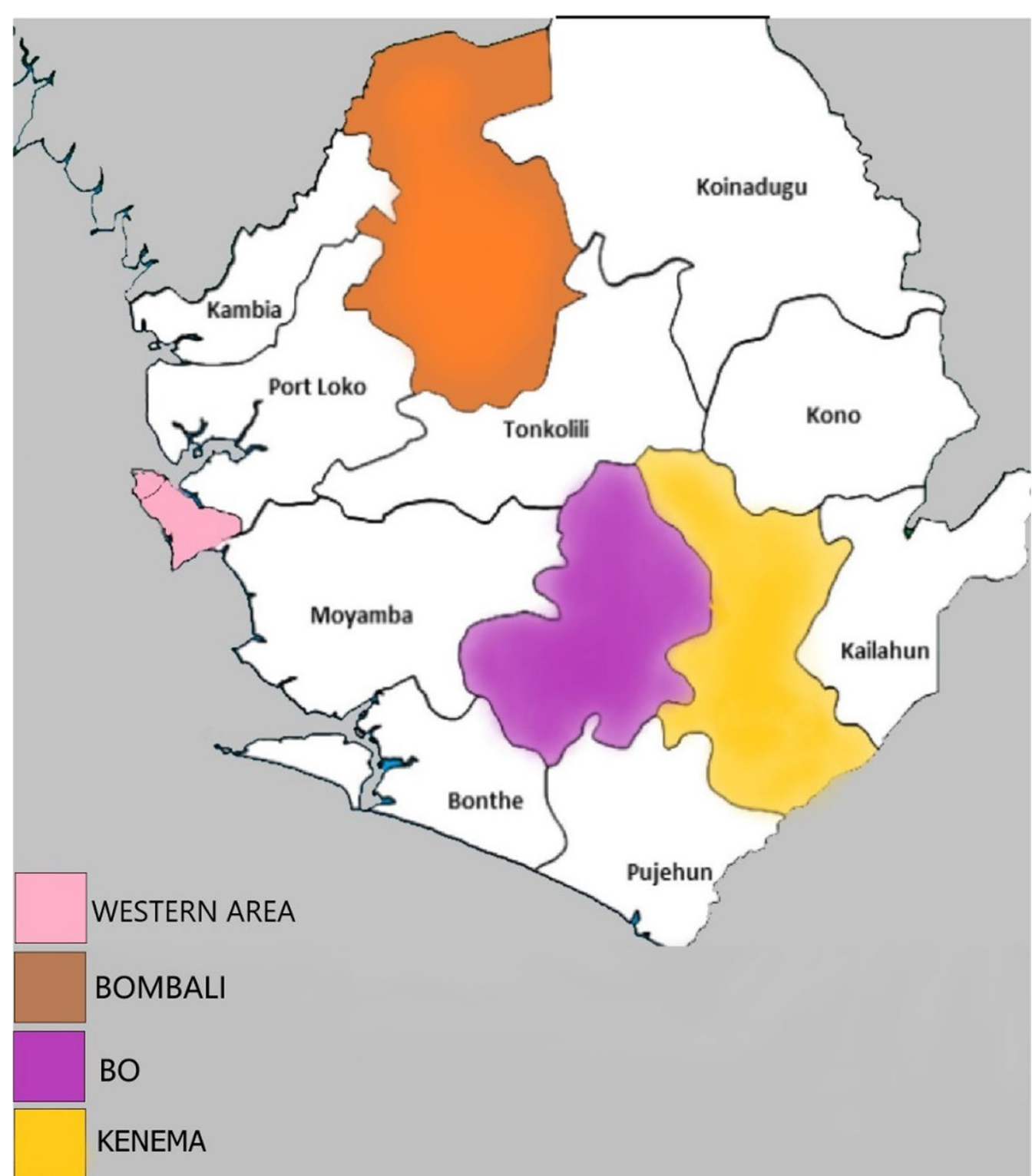

Fig. 2 Locations of the five districts (Western area urban, Western area rural, Bombali, Bo and Kenema) in Sierra Leone. ( Source: Map created by the authors)

AIDS patients in five African countries, including Lesotho, Malawi, South Africa, Swaziland, and Tanzania [29]. HASI-P consist of two major subscales, and this includes negative self-perception, which measures internalised stigma and enacted stigma. The enacted stigma subscale measures undesirable responses from the community expressed against those with the stigmatising attributes including verbal abuse, healthcare neglect, social isolation, fear of contagion and workplace stigma. We decided to use HASI-P in our study because HIV/AIDS patients and EVD survivors experience similar psycho-social difficulties regarding their social status stemming from internal and external sources [30]. There is also misinformation regarding the causes and mode of transmission of both diseases and the type of people affected in the community. We modified the HASI-P instrument to fit our local context. Following feedback from experts and a pilot test for face validity among 10 EVD survivors, we removed the two items that measured workplace stigma since close to half of EVD survivors were unemployed. In addition, given that majority of EVD survivors were not hospital inpatients after discharge from ETC, 
we removed one item (I was left in soiled bed") from the healthcare neglect subscale. The adapted HASI-P instrument has been published elsewhere [10]. Each of the 30 stigma items was given a score of $0-3(0=$ never, $1=$ once or twice, $2=$ several times and three $=$ most of the time) to measure the frequency an EVD survivor experienced each of the investigated events. We added the scores and divided them by the number of items to get the average score of each subscale for each EVD survivor. We checked the internal consistency reliability for this instrument in this study, and the Cronbach alpha value was 0.828. Also, the Cronbach alpha values for internal and enacted stigma subscales in this study were 0.855 and 0.815 respectively.

\section{Health-related quality of life}

We used the RAND 36-Item Health Survey version 1.0 (SF-36v1). SF-36 is a patient self-report instrument that assessed eights domains. The domains include general health (6 items), physical functioning (10 items), role limitation due to physical health ( 4 items), body pain (2 items), vitality (4 items), social functioning (2 items), role limitation due to emotional problem (3 items), and mental health (4 items). RAND SF-36 instrument has been used to measure the HRQoL of survivors of emerging and re-emerging infectious diseases such as SARS, MERS, and COVID-19 $[14,17,19]$. It has also been used in African countries with good reliability measures [31-34]. We scored the items as per the instructions provided by the scoring manual [35]. First, we recoded the precoded values as per scoring instructions. Second, we calculated the mean of all items on the same domain scale to generate the eight domain scale scores. Scores for each domain ranged from 0 to 100, with the highest score representing a favourable HRQoL. The eight domains were grouped into physical (PCS) and mental (MCS) component summary scales as described by Farivar et al. [36]. PCS and MCS were calculated by multiplying the z-score of each domain scale with its respective physical and mental factor scoring coefficients (weights) and summing all eight products to obtain an aggregate physical and mental scale. These aggregate physical and mental standardised scales were then standardised by multiplying each of the aggregate by 10 and adding the resulting product to 50 . Given that Sierra Leone and no other country in Africa does not have a population norm, we decided to use the United States population norm while adapting the SF-36 The scoring of the physical (PCS) and mental (MCS) component summary scales were scored using methods described by Ware et al. [37]. The internal consistency reliability for this instrument for this study was checked, and the Cronbach alpha value for the whole RAND SF-36 instrument was $\alpha=0.918$.

\section{Data collection and ethical consideration}

We used self-administered or interviewer-administered (for illiterate participants) formats to collect the relevant data from EVD survivors. We collected our data between May and August 2018, and it was done either in the offices of EVD survivors or homes or village courtyard. We obtained ethics approval to conduct the study from the Sierra Leone Ethics and Scientific Review Committee. EVD survivors were informed about the scope and nature of the study as well as the freedom to opt at any time. Written consent to participate in the study was obtained from each survivor before being interviewed. Consent to participate in the study was interpreted by signing or thumb printing (for illiterate participants) the consent form.

\section{Data analysis}

We used IBM SPSS Statistics version 27 to analyse our data. We represented categorical variables using frequencies, and percentages, and median and interquartile range for continuous variables. Bivariate analysis was employed using median test (continuous variables) and Chi square test (categorical variable). We used univariate linear regression analysis to calculate the effect size ( $\beta$-coefficient). Independent variables with $p$ values less than 0.1 in the univariate linear regression analysis were moved into the multivariate model to determine the socio-demographic, health and psycho-social variables independently associated with, PCS and MCS. To compute the univariate and multivariate linear regression, we created dummy variables for categorical variables with more than two categories. Independent variables were considered statistically significant in the multiple linear regression analysis if their $p$ values were less than 0.05 .

\section{Results}

Out of the 377 EVD survivors who consented to participate in the study, 358 completed all items of the questionnaire, and were included in the data analysis. Majority $[n=328(91.6 \%)]$ were in the age group of $18-49$ years with no significant difference between males and females $[\mathrm{n}=128(94.8 \%)$ vs $\mathrm{n}=200$ (89.7\%), $p=0.115]$. Close to a quarter were divorced/Separated/widowed [87 (24.3)], and more males than females were divorced/Separated/ widowed [ $\mathrm{n}=87(24.3 \%)$ vs $\mathrm{n}=11(8.1 \%), p=0.001]$. The median number of post-Ebola symptoms was 5.00 (3.00) and no significant difference was observed between males and females [4.00 (3.00) vs. 5.00 (3.00) $p=0.088$ ]. The median time spent at the Ebola treatment centre was 21.00 (14.00) days and a gender difference was observed [males $=21.00(15.00)$ vs. females $=23.00$ (14.00), $p=0.036]$. Majority reported to be experiencing joint pain $[n=319(89.1 \%)]$ with no significant difference 
between males and females $[\mathrm{n}=119(88.1 \%)$ vs. $\mathrm{n}=200$ (89.7), $p=0.651]$. Alopecia was reported in approximately one in ten EVD survivors $[\mathrm{n}=38(10.6 \%)]$ with more women $[n=30(13.5 \%)]$ than men $[n=8(5.9 \%)]$ reporting it. The median internalised stigma score was $[$ median $=0.80 \quad(\mathrm{IQR}=1.00)]$ and the median enacted stigma score was $[$ median $=0.54(\mathrm{IQR}=0.80)]$. Females had higher enacted stigma than their male counterparts $[$ median $=0.67 \quad(\mathrm{IQR}=0.96) \quad$ vs. median $=0.42$ $(\mathrm{IQR}=0.63) ; p=0.005]$.

Table 1 provides further details.

\section{Health-related quality of life of EVD survivors}

Table 2 shows the eight domain scales of the SF-36 and their component summary scales (PCS and MCS) median scores of EVD survivors. When comparing by each dimension in relation to their respective summary scores, role limitation physical $[0.00(50.00)]$ and role limitation emotional [0.00 (33.33)] were the most affected physical health domain and mental health domains among EVD survivors respectively Among the eight domains, EVD survivors had the highest [52.00 (12.00)] median score for emotional wellbeing and the lowest median score for role limitation-Physical emotional [0.00 (33.33)]. Significant gender differences were observed in the physical functioning $(p<0,001)$. The mental health composite median score was [33.12 (6.79)] whilst the physical health composite median score was [30.05 (9.57)], although there was no statistically significant gender difference $(p=1.00)$.

When comparing the HRQoL by each dimension in relation to their respective summary scores, Role limitation physical was the most affected physical health domain among EVD survivors. Similarly, role limitation emotional was the was the most affected mental health domain among EVD survivors.

\section{Factors associated with health-related quality of life among EVD survivors}

Table 3 shows details of the univariate analysis. EVD survivors who were older $(\beta=-6.74,95 \% \mathrm{CI}-9.59$ to $-3.89, p<0.001)$, did not go to school $(\beta=-5.18,95 \%$ CI -7.80 to $-2.56, p<0.001)$ widowed $(\beta=-3.85,95 \%$ CI -6.11 to $-1.60, p=0.001)$ and have a unit increase in the number of post-Ebola symptoms $(\beta=-1.45,95 \%$ $\mathrm{CI}-1.88$ to $-1.01, p<0.001$ ) were more likely to report a decreased level of PCS. Similar associations were observed for MCS. Table 4 summarises the demographic, health-related, and psycho-social factors independently associated with the physical health composite score among EVD survivors. We found that EVD survivors who were 50 years and older were more likely to report a decrease in physical health $(\beta=-3.90,95 \% \mathrm{CI}-6.47$ to $-1.32, p=0.003$ ), compared to those below 50 years. Also, EVD survivors with no formal education were more likely to report a decrease in physical health $(\beta=-2.80$, $95 \% \mathrm{CI}-5.16$ to $-0.43, p=0.021$ ) than participants with a tertiary education. In addition, a unit increase in the number of post-Ebola symptoms was correlated with participants' lower physical health $(\beta=-1.08,95 \%$ CI -1.74 to $-0.43, p<0.001)$. Further, EVD survivors who experienced a unit increase in enacted stigma were more likely to report a decreased level of physical health $(\beta=-2.61,95 \% \mathrm{CI}-4.02$ to $-1.20, p<0.001)$.

Table 5 shows the demographic, health-related, and psycho-social factors associated with the mental health composite score among Ebola survivors. EVD survivors with a unit increase in the time spent in the Ebola treatment centre were likely to report a decrease in mental health $(\beta=-0.60,95 \% \mathrm{CI}-0.103$ to $-0.18, p=0.006)$. Also, EVD survivors who experienced a unit increase in Enacted Stigma were more likely to report a decreased level of mental health $(\beta=-1.50,95 \% \mathrm{CI}-2.67$ to -0.33 , $p=0.012$ ).

\section{Discussion}

Our study sought to explore the association between social factors (demographic, health-related, and psychosocial) and HRQoL among Ebola survivors. We found a low physical health and mental health summary scores, indicating that EVD survivors maybe suffering from poor physical and mental health. This finding is in line with previous Sierra Leonean studies, which show that EVD survivors continue to experience poor physical and mental health more than two and half years after discharge from the Ebola treatment centre [11, 12, 38]. EVD survivors continue to suffer from psychological distress due to grief resulting from losing loved ones, social exclusion, and community stigmatisation $[6,23]$. Furthermore, we observed a lower score for physical role limitation, a key component of the physical health in our study, suggesting that EVD survivors may face limitations in performing basic daily physical activities. Mobility limitation has been reported to be a common post-Ebola disability. For example, a previous study in Sierra Leone has found that EVD survivors had significant limitations in walking and climbing stairs a year after recovery, and musculoskeletal pain was a contributing factor [9]. Regarding the mental health of EVD survivors, recent Sierra Leonean studies have shown that anxiety, depression, posttraumatic stress disorder and stigma are common among EVD survivors $[10,11,38]$. Our findings regarding the physical and mental health limitations among EVD survivors further emphasised the need for them to access 
Table 1 Sociodemographic, Health related, and Psycho-social (Ebola related stigma) characteristics of Ebola survivors ( $N=358)$

\begin{tabular}{|c|c|c|c|c|c|}
\hline Characteristics & Variables & $\begin{array}{l}\mathrm{n}(\%) \text { mean } \pm \mathrm{SD} \\
\text { median (interquartile } \\
\text { range) }\end{array}$ & $\begin{array}{l}\text { Male } \mathrm{n}(\%) \text { median } \\
\text { (interquartile } \\
\text { range) }\end{array}$ & $\begin{array}{l}\text { Female } \mathrm{n}(\%) \text { Median } \\
\text { (interquartile range) }\end{array}$ & $p$ value \\
\hline \multicolumn{6}{|l|}{ Sociodemographic characteristics } \\
\hline \multirow[t]{2}{*}{ Age group } & $18-49$ years & $328(91.6)$ & $128(94.8)$ & $200(89.7)$ & 0.115 \\
\hline & $\geq 50$ years & $30(8.4)$ & $7(5.2)$ & $23(10.3)$ & \\
\hline \multirow[t]{2}{*}{ Religion } & Christianity & $92(25.7)$ & $27(20.0)$ & $65(29.1)$ & 0.062 \\
\hline & Islam & $266(74.3)$ & $108(80.0)$ & $158(70.9)$ & \\
\hline \multirow[t]{4}{*}{ Education status } & Non-formal education & $147(41.1)$ & $43(31.9)$ & $104(46.6)$ & 0.012 \\
\hline & Primary & $44(12.3)$ & $15(11.1)$ & $29(13.0)$ & \\
\hline & Secondary & $126(35.2)$ & $61(45.2)$ & $65(29.1)$ & \\
\hline & Tertiary & $41(11.5)$ & $16(11.9)$ & $25(11.2)$ & \\
\hline \multirow[t]{3}{*}{ Marital status } & Single & $100(27.9)$ & $36(26.7)$ & $64(28.7)$ & $<0.001$ \\
\hline & Married/cohabitating & $171(47.8)$ & $88(65.2)$ & $83(37.2)$ & \\
\hline & Divorced/separated/widowed & $87(24.3)$ & $11(8.1)$ & $76(34.1)$ & \\
\hline \multirow[t]{2}{*}{ Residence } & Urban & $219(61.2)$ & $80(59.3)$ & $139(62.3)$ & 0.563 \\
\hline & Rural & $139(38.8)$ & $55(40.7)$ & $84(37.7)$ & \\
\hline \multirow[t]{3}{*}{ Economic status } & Difficult all the time & $110(30.7)$ & $42(31.1)$ & $68(30.5)$ & 0.930 \\
\hline & difficult some time & $238(66.5)$ & $90(66.7)$ & $148(66.4)$ & \\
\hline & Not too bad/easy & $10(2.8)$ & $3(2.2)$ & $7(3.1)$ & \\
\hline \multirow[t]{4}{*}{ Region } & Northern region & $120(33.5)$ & $47(34.8)$ & $73(32.7)$ & 0.346 \\
\hline & Southern region & $55(15.4)$ & $19(14.1)$ & $36(16.1)$ & \\
\hline & Eastern region & $62(17.3)$ & $18(13.3)$ & $44(19.7)$ & \\
\hline & Western area & 121(33.8) & $51(37.8)$ & $70(31.4)$ & \\
\hline \multirow[t]{2}{*}{ Known chronic health } & Yes & $46(12.8)$ & $16(11.9)$ & $30(13.5)$ & 0.661 \\
\hline & No & $312(87.2)$ & $119(88.1)$ & $193(86.5)$ & \\
\hline \multirow{2}{*}{$\begin{array}{l}\text { Employment status after surviv- } \\
\text { ing Ebola }\end{array}$} & Employed & $199(55.6)$ & $66(48.9)$ & $133(59.6)$ & 0.049 \\
\hline & Unemployed & $159(44.4)$ & $69(51.1)$ & $90(40.4)$ & \\
\hline \multicolumn{6}{|l|}{ Health-related characteristics } \\
\hline \multirow[t]{2}{*}{ Current perceived health status } & Very good/good & $96(26.8)$ & $44(32.6)$ & $52(23.3)$ & 0.055 \\
\hline & Fair/poor & $262(73.2)$ & $91(67.4)$ & $171(76.7)$ & \\
\hline Time (days) spent at ETC & & $21.00(14.00)$ & $21.00(15.00)$ & $23.00(14.00)$ & 0.036 \\
\hline $\begin{array}{l}\text { Duration (months) since dis- } \\
\text { charged from ETC }\end{array}$ & & $42.00(4.00)$ & $42.00(4.00)$ & $42.00(4.00)$ & 0.922 \\
\hline Burden of post-Ebola symptoms & & $5.00(3.00)$ & $4.00(3.00)$ & $5.00(3.00)$ & 0.088 \\
\hline \multirow[t]{2}{*}{ Arthralgia (Joint pain) } & Yes & $319(89.1)$ & $119(88.1)$ & $200(89.7)$ & 0.651 \\
\hline & No & $39(10.9)$ & $16(11.9)$ & $23(10.3)$ & \\
\hline \multirow[t]{2}{*}{ Headache } & Yes & $272(76.0)$ & $103(76.3)$ & $169(75.8)$ & 0.913 \\
\hline & No & $86(24.0)$ & $32(23.7)$ & $54(24.2)$ & \\
\hline \multirow[t]{2}{*}{ Ocular symptoms } & Yes & $206(57.5)$ & 75 (55.6) & $131(58.7)$ & 0.554 \\
\hline & No & $152(42.5)$ & $60(44.4)$ & $92(41.3)$ & \\
\hline \multirow[t]{2}{*}{ Fatigue } & Yes & $181(50.6)$ & $73(54.1)$ & $108(48.4)$ & 0.301 \\
\hline & No & $177(49.4)$ & $62(45.9)$ & $115(51.6)$ & \\
\hline \multirow[t]{2}{*}{ Back pain } & Yes & $179(50.0)$ & $60(44.4)$ & $119(53.4)$ & 0.102 \\
\hline & No & $179(50.0)$ & 75 (55.6) & $104(46.6)$ & \\
\hline \multirow[t]{2}{*}{ Abdominal pain } & Yes & $132(36.9)$ & $38(28.1)$ & $94(42.2)$ & 0.008 \\
\hline & No & $226(63.1)$ & $97(71.9)$ & $129(57.8)$ & \\
\hline \multirow[t]{2}{*}{ Auditory symptoms } & Yes & $61(17.0)$ & $21(15.6)$ & 40 (17.9) & 0.561 \\
\hline & No & $297(83.0)$ & $114(84.4)$ & $183(82.1)$ & \\
\hline Skin Disorder & Yes & $55(15.4)$ & $21(15.6)$ & $34(15.2)$ & 0.937 \\
\hline
\end{tabular}


Table 1 (continued)

\begin{tabular}{|c|c|c|c|c|c|}
\hline Characteristics & Variables & $\begin{array}{l}\mathrm{n}(\%) \text { mean } \pm \mathrm{SD} \\
\text { median (interquartile } \\
\text { range) }\end{array}$ & $\begin{array}{l}\text { Male } \mathbf{n}(\%) \text { median } \\
\text { (interquartile } \\
\text { range) }\end{array}$ & $\begin{array}{l}\text { Female } \mathrm{n}(\%) \text { Median } \\
\text { (interquartile range) }\end{array}$ & $p$ value \\
\hline & No & $303(84.6)$ & $114(84.4)$ & $189(84.8)$ & \\
\hline \multirow[t]{2}{*}{ Alopecia } & Yes & $38(10.6)$ & $8(5.9)$ & $30(13.5)$ & 0.025 \\
\hline & No & $320(89.4)$ & $127(94.1)$ & $193(86.5)$ & \\
\hline \multicolumn{6}{|c|}{ Psycho-social characteristics (Ebola-related stigma) } \\
\hline \multicolumn{2}{|c|}{$\begin{array}{l}\text { Internalized stigma (negative self- } \\
\text { perception) }\end{array}$} & $0.80(1.00)$ & $0.60(1.00)$ & $0.80(1.00)$ & 0.072 \\
\hline \multicolumn{2}{|c|}{ Enacted stigma } & $0.54(0.80)$ & $0.42(0.63)$ & $0.67(0.96)$ & 0.005 \\
\hline
\end{tabular}

comprehensive healthcare that includes specialist care

Table 2 HRQOL among Ebola survivors

\begin{tabular}{|c|c|c|c|c|}
\hline SF-36 domains & $\begin{array}{l}\text { Median (interquartile } \\
\text { range) }\end{array}$ & $\begin{array}{l}\text { Male median (interquartile } \\
\text { range) }\end{array}$ & $\begin{array}{l}\text { Female median } \\
\text { (interquartile range) }\end{array}$ & $p$ value \\
\hline General health & $35.00(20.00)$ & $35.00(20.00)$ & $30.00(15.00)$ & 0.761 \\
\hline Physical Functioning & $50.00(35.00)$ & $55.00(30.00)$ & $45.00(30.00)$ & $<0.001$ \\
\hline Role limitation_Physical & $0.00(50.00)$ & $0.00(50.00)$ & $0.00(50.00)$ & 0.477 \\
\hline Role limitation-Emotional & $0,00(33.33)$ & $0.00(33.33)$ & $0.00(66.67)$ & 0.129 \\
\hline Energy-fatigue (vitality) & $45.00(15.00)$ & $45.00(15.00)$ & $40.00(15.00)$ & 0.094 \\
\hline Emotional wellbeing (mental health) & $52.00(12.00)$ & $52.00(12.00)$ & $52.00(12.00)$ & 0.766 \\
\hline Social Functioning & $50.00(25.00)$ & $50.00(12.50)$ & $50.00(25.00)$ & 0.766 \\
\hline Bodily pain & $35.00(32.50)$ & $35.00(35.00)$ & $35.00(22.50)$ & 0.441 \\
\hline Physical Health (PCS) & $30.05(9.57)$ & $30.70(10.63)$ & $29.53(9.00)$ & 0.275 \\
\hline Mental health (MCS) & $33.12(6.79)$ & $33.18(6.71)$ & $33.12(6.87)$ & 1.000 \\
\hline
\end{tabular}

disturbance [43, 44]. Regarding gender, a recent study and mental health services $[39,40]$.

In our study, age, educational status, the burden of post-Ebola symptoms, and enacted stigma were significantly associated with a decreased physical component score depicting poor physical health of EVD survivors. Our study shows that older EVD survivors had higher odds of having decreased levels of mental health. Similar findings have been reported among patients living with chronic health conditions, in which older patients were more likely to report poorer quality of life than younger ones [41, 42]. However, our result was inconsistent with a recent Chinese study among COVID-19 survivors, which reported no association between age and physical component score [19] which may reflect differences in biologic and socio-cultural contexts. The link between age and physical health in our study may be due to the physiological changes accompanying old age and the loss of capacity to fully undertake activities of daily living as well as the incremental activities of daily tasks. Also, older individuals are more likely to suffer from chronic pain, experience challenges in pain management, leading to functional impairment, falls, depression, and sleep among COVID-19 survivors reported that being female was a significant determinant of reduced physical health [19]. This prior observation is inconsistent with our finding in which there was no significant gender difference. We also observed in our study that EVD survivors with no formal education were more likely to report decreased physical health compared to those with college education. A similar finding was reported among patients with stroke at tertiary level hospital in Ethiopia in which stroke survivors who did not go to school were likely to report lower physical health scores than those that went to school [45]. Our finding might be explained in that EVD survivors who cannot read and write have lower levels of understanding of their physical health and psychological issues and inability to make informed decisions regarding the choice of appropriate treatment options, including selfcare.

We also observed that as the burden of post-Ebola symptoms increases, physical and mental health of EVD survivors decreases, suggesting that the higher the number of post-Ebola physical health symptoms a survivor has, the more significant the impact on his/her HRQoL. 
Table 3 Univariate Analysis of the factors associated with physical health composite score, mental health composites and overall health related quality of life among Ebola survivors

\begin{tabular}{|c|c|c|c|c|c|c|c|}
\hline \multirow[t]{2}{*}{ Characteristics } & \multirow[t]{2}{*}{ Variables } & \multicolumn{3}{|l|}{ PCS } & \multicolumn{3}{|l|}{ MCS } \\
\hline & & $\beta$ & $95 \% \mathrm{Cl}$ & $p$ value & $\beta$ & $95 \% \mathrm{Cl}$ & $p$ value \\
\hline \multirow[t]{2}{*}{ Sex } & Male & 1.55 & $-0.11,-3.22$ & 0.068 & 0.15 & $-1.217,1.509$ & 0.833 \\
\hline & Female & Ref & & & Ref & & \\
\hline \multirow[t]{2}{*}{ Age group } & $18-49$ & Ref & & & Ref & & $<0.001$ \\
\hline & $\geq 50$ years & -6.74 & $-9.59,-3.89$ & $<0.001$ & -4.82 & $-7.15,-2.49$ & \\
\hline \multirow[t]{2}{*}{ Religion } & Christianity & -0.59 & $-2.45,1.27$ & 0.534 & -0.18 & $-1.69,1.33$ & 0.813 \\
\hline & Islam & Ref & & & Ref & & \\
\hline \multirow[t]{4}{*}{ Education status } & Non-formal & -5.18 & $-7.80,-2.56$ & $<0.001$ & -3.70 & $-5.87,-1.54$ & $<0.001$ \\
\hline & Primary & -0.68 & $-3.90,2.53$ & 0.676 & -0.81 & $-3.47,1.85$ & 0.548 \\
\hline & Secondary & -1.13 & $-3.80,1.53$ & 0.404 & -1.74 & $-3.94,0.46$ & 0.121 \\
\hline & Tertiary & Ref & & & Ref & & \\
\hline \multirow[t]{4}{*}{ Marital Status } & Single & Ref & & & Ref & & \\
\hline & Married/cohabitating & -1.162 & $-3.07,0.75$ & 0.233 & -0.13 & $-1.68,1.43$ & 0.874 \\
\hline & Divorce /separated/ & -1.41 & $-9.15,6.33$ & 0.721 & 2.85 & $-3.45,9.14$ & 0.375 \\
\hline & widowed & -3.85 & $-6.11,-1.60$ & 0.001 & -2.50 & $-4.33,-0.67$ & 0.008 \\
\hline \multirow[t]{2}{*}{ Residence } & urban & 0.92 & $-0.75,2.58$ & 0.281 & 0.72 & $-0.63,2.07$ & 0.294 \\
\hline & Rural & Ref & & & Ref & & \\
\hline \multirow[t]{3}{*}{ Economic Status } & Impossible/difficult all time & -3.73 & $-8.79,1.33$ & 0.148 & -2.03 & $-6.10,2.05$ & 0.329 \\
\hline & Difficult sometimes & -2.19 & $-7.13,2.76$ & & 0.29 & $-3.70,4.27$ & \\
\hline & Not too bad/easy & Ref & & 0.385 & Ref & & 0.887 \\
\hline \multirow[t]{4}{*}{ Region } & Northern region & -5.04 & $-6.95,-3.13$ & $<0.001$ & -2.60 & $-4.19,-1.01$ & 0.001 \\
\hline & Southern region & -0.70 & $-3.10,1.72$ & 0.571 & -1.18 & $-3.19,0.83$ & 0.249 \\
\hline & Eastern region & -2.49 & $-4.81,-0.18$ & 0.035 & -1.17 & $-3.10,0.76$ & 0.232 \\
\hline & Western area & Ref & & & Ref & & \\
\hline \multirow[t]{2}{*}{ Known chronic condition } & Yes & -0.35 & $-2.78,2.08$ & 0.777 & -0.08 & $-2.06,1.89$ & 0.935 \\
\hline & No & Ref & & & Ref & & \\
\hline \multirow[t]{2}{*}{ Employment status after surviving Ebola } & Employed & Ref & & & Ref & & \\
\hline & Not employed & -0.38 & $-2.02,1.25$ & 0.647 & -1.18 & $-2.51,0.14$ & 0.080 \\
\hline \multirow[t]{2}{*}{ Current perceived health status } & Very good/good & Ref & & & Ref & & \\
\hline & Fair/poor & -5.14 & $-6.89,-3.38$ & $<0.001$ & -5.44 & $-6.82,-4.06$ & $<0.001$ \\
\hline Duration (months) since discharged from ETC & & -0.07 & $-0.29,0.14$ & 0.502 & -0.05 & $-0.23,0.12$ & 0.536 \\
\hline Time spent at ETC & & -0.08 & $-0.15,-0.01$ & 0.018 & -0.09 & $-0.15,-0.04$ & $<0.001$ \\
\hline Number of post-Ebola symptoms & & -1.45 & $-1.88,-1.01$ & $<0.001$ & -0.96 & $-1.32,-0.60$ & $<0.001$ \\
\hline \multirow[t]{2}{*}{ Arthralgia (Joint pain) } & Yes & -2.69 & $-5.29,-0.10$ & 0.042 & -1.16 & $-3.28,0.96$ & 0.283 \\
\hline & No & ref & & & ref & & \\
\hline \multirow[t]{2}{*}{ Headache } & Yes & 0.08 & $-1.82,1.99$ & 0.931 & -0.73 & $-2.27,0.82$ & 0.357 \\
\hline & No & Ref & & & Ref & & \\
\hline \multirow[t]{2}{*}{ Ocular symptoms } & Yes & -3.77 & $-5.36,-2.17$ & $<0.001$ & -2.55 & $-3.86,1.24$ & $<0.001$ \\
\hline & No & Ref & & & Ref & & \\
\hline \multirow[t]{2}{*}{ Fatigue } & Yes & -2.62 & $-4.22,-1.01$ & 0.001 & 1.08 & $-2.39,0.24$ & 0.109 \\
\hline & No & Ref & & & Ref & & \\
\hline \multirow[t]{2}{*}{ Back pain } & Yes & -1.51 & $-3.13,0.11$ & 0.067 & -0.85 & $-2.17,0.47$ & 0.205 \\
\hline & No & Ref & & & Ref & & \\
\hline \multirow[t]{2}{*}{ Abdominal pain } & Yes & -0.52 & $-2.20,1.17$ & 0.544 & -1.08 & $-2.44,0.29$ & 0.121 \\
\hline & No & Ref & & & Ref & & \\
\hline Auditory symptoms & Yes & -2.19 & $-4.34,-0.04$ & 0.046 & -1.28 & $-3.03,0.48$ & 0.153 \\
\hline & No & Ref & & & Ref & & \\
\hline Skin disorders & Yes & -3.64 & $-5.86,-2.140$ & 0.001 & -2.16 & $-3.98,0.34$ & 0.020 \\
\hline
\end{tabular}


Table 3 (continued)

\begin{tabular}{|c|c|c|c|c|c|c|c|}
\hline \multirow[t]{2}{*}{ Characteristics } & \multirow[t]{2}{*}{ Variables } & \multicolumn{3}{|l|}{ PCS } & \multicolumn{3}{|l|}{ MCS } \\
\hline & & $\beta$ & $95 \% \mathrm{Cl}$ & $p$ value & $\beta$ & $95 \% \mathrm{Cl}$ & $p$ value \\
\hline & No & Ref & & & Ref & & \\
\hline \multirow[t]{2}{*}{ Alopecia } & Yes & -1.37 & $-4.01,1.26$ & 0.306 & -0.85 & $-2.99,1.30$ & 0.438 \\
\hline & No & Ref & & & Ref & & \\
\hline $\begin{array}{l}\text { Internalized stigma (negative self-perception } \\
\text { subscale }\end{array}$ & & -2.89 & $-3.90,-1.87$ & $<0.001$ & -2.68 & $-3.50,-1.86$ & $<0.001$ \\
\hline Enacted stigma & & -3.17 & $-4.46,-1.88$ & $<0.001$ & -2.58 & $-3.63,-1.53$ & $<0.001$ \\
\hline
\end{tabular}

Table 4 Multiple linear regression analysis to identify factors associated with Physical Health (PCS) among Ebola survivors (N=358)

\begin{tabular}{|c|c|c|c|c|c|c|}
\hline \multirow[t]{2}{*}{ Characteristics } & \multirow[t]{2}{*}{ Variable } & \multicolumn{2}{|c|}{$\begin{array}{l}\text { Unstandardized } \\
\text { coefficients }\end{array}$} & \multicolumn{2}{|l|}{$95 \% \mathrm{Cl}$} & \multirow[t]{2}{*}{$p$ value } \\
\hline & & $\beta$ & SE & Lower & Upper & \\
\hline \multirow[t]{2}{*}{ Sex } & Female & Ref & & - & & \\
\hline & Male & -0.04 & 0.76 & -1.54 & 1.45 & 0.956 \\
\hline \multirow[t]{2}{*}{ Age group } & $18-49$ & Ref & & & & \\
\hline & $\geq 50$ years & -3.90 & 1.31 & -6.47 & -1.32 & 0.003 \\
\hline \multirow[t]{4}{*}{ Educational status } & Non-formal & -2.80 & 1.202 & -5.160 & -0.43 & 0.021 \\
\hline & Primary & -0.25 & 1.44 & -3.09 & 2.59 & 0.862 \\
\hline & Secondary & -0.79 & 1.232 & -3.21 & 1.635 & 0.523 \\
\hline & Tertiary & Ref & & & & \\
\hline \multirow[t]{4}{*}{ Marital status } & Single & Ref & & & & \\
\hline & Married/cohabitating & 0.48 & 0.946 & -1.38 & 2.34 & 0.614 \\
\hline & Divorce/separated/ & -1.51 & 3.407 & -8.21 & 5.20 & 0.659 \\
\hline & widowed & 0.47 & 1.19 & -1.86 & 2.81 & 0.691 \\
\hline \multirow[t]{4}{*}{ Region } & Northern region & -5.47 & 0.90 & -7.25 & -3.69 & $<0.001$ \\
\hline & Southern region & -1.66 & 1.13 & -3.88 & 0.57 & 0.144 \\
\hline & Eastern region & 0.09 & 1.19 & -2.24 & 2.43 & 0.937 \\
\hline & Western area & Ref & & & & \\
\hline \multirow[t]{2}{*}{ Perceived health status } & Fair/poor & -3.68 & 0.87 & -5.38 & -1.98 & $<0.001$ \\
\hline & Very good/good & Ref & & & & \\
\hline Number of post Ebola symptoms reported & & -1.08 & 0.33 & -1.74 & -0.431 & $<0.001$ \\
\hline Time spent at ETC & & -0.01 & 0.03 & -0.06 & 0.05 & 0.805 \\
\hline \multirow[t]{2}{*}{ Ocular symptoms } & Yes & -1.077 & 0.804 & -2.659 & 0.51 & 0.181 \\
\hline & No & Ref & & & & \\
\hline \multirow[t]{2}{*}{ Fatigue } & Yes & -1.71 & 0.74 & -3.17 & -0.25 & 0.022 \\
\hline & No & Ref & & & & \\
\hline \multirow[t]{2}{*}{ Skin disorder } & Yes & -0.45 & 1.08 & -2.58 & 1.68 & 0.676 \\
\hline & No & Ref & & & & \\
\hline \multirow[t]{2}{*}{ Arthralgia (joint pain) } & Yes & 1.05 & 1.22 & -1.36 & 3.45 & 0.392 \\
\hline & No & Ref & & & & \\
\hline \multirow[t]{2}{*}{ Auditory symptoms } & Yes & -0.08 & 1.04 & -2.13 & 1.96 & 0.936 \\
\hline & No & Ref & & & & \\
\hline Internalised stigma (negative self-perception) & & -0.10 & 0.61 & -1.29 & 1.09 & 0.875 \\
\hline Enacted stigma & & -2.61 & 0.72 & -4.02 & -1.20 & $<0.001$ \\
\hline
\end{tabular}


Table 5 Multiple linear regression analysis to identify factors associated with MCS among Ebola survivors $(\mathrm{N}=358)$

\begin{tabular}{|c|c|c|c|c|c|c|}
\hline \multirow[t]{2}{*}{ Characteristics } & \multirow[t]{2}{*}{ Variable } & \multicolumn{2}{|c|}{$\begin{array}{l}\text { Unstandardized } \\
\text { coefficients }\end{array}$} & \multicolumn{2}{|l|}{$95 \% \mathrm{Cl}$} & \multirow[t]{2}{*}{$p$ value } \\
\hline & & $\beta$ & SE & Lower & Upper & \\
\hline \multirow[t]{2}{*}{ Age group } & $\geq 50$ years & -2.61 & 1.10 & -4.77 & -0.44 & 0.018 \\
\hline & $18-49$ years & Ref & & & & \\
\hline \multirow[t]{4}{*}{ Educational status } & Non-formal & -1.76 & 0.10 & -3.73 & 0.20 & 0.078 \\
\hline & Primary & -0.21 & 1.20 & -2.57 & 2.16 & 0.863 \\
\hline & Secondary & -1.19 & 1.03 & -3.22 & 0.847 & 0.252 \\
\hline & Tertiary & Ref & & & & \\
\hline \multirow[t]{4}{*}{ Marital status } & Single & Ref & & & & \\
\hline & Married/cohabitating & 0.53 & 0.79 & -1.02 & 2.08 & 0.500 \\
\hline & Divorce/separated/ & 3.30 & 2.85 & -2.30 & 8.90 & 0.247 \\
\hline & widowed & 0.58 & 0.99 & -1.36 & 2.52 & 0.556 \\
\hline \multirow[t]{4}{*}{ Region } & Northern region & -3.03 & 0.76 & -4.53 & -1.54 & $<0.001$ \\
\hline & Southern region & -2.09 & 0.94 & -3.95 & -0.24 & 0.027 \\
\hline & Eastern region & 0.54 & 0.96 & -1.34 & 2.43 & 0.571 \\
\hline & Western area & Ref & & & & \\
\hline \multirow[t]{2}{*}{ Employment status after surviving Ebola } & Not employed & -0.65 & 0.65 & -1.92 & 0.62 & 0.318 \\
\hline & Employed & Ref & & & & \\
\hline \multirow[t]{2}{*}{ Perceived health status } & Fair/poor & -4.28 & 0.72 & -5.69 & -2.88 & $<0.001$ \\
\hline & Very good/good & Ref & & & & \\
\hline Time spent at ETC (days) & & -0.04 & 0.02 & -0.09 & 0.01 & 0.098 \\
\hline Number of post ebola symptoms reported & & -0.60 & 0.22 & -1.03 & -0.18 & 0.006 \\
\hline \multirow[t]{2}{*}{ Ocular symptoms } & Yes & -0.76 & 0.65 & -2.03 & 0.51 & 0.239 \\
\hline & No & Ref & & & & \\
\hline \multirow[t]{2}{*}{ Skin disorder } & Yes & -0.20 & 0.90 & -1.97 & 1.57 & 0.822 \\
\hline & No & Ref & & & & \\
\hline Enacted stigma & & -1.50 & 0.59 & -2.67 & -0.33 & 0.012 \\
\hline Internalised stigma (negative perception) & & -0.52 & 0.50 & -1.51 & 0.47 & 0.300 \\
\hline
\end{tabular}

A similar finding has been reported among COVID-19 survivors [20] and co-morbid diabetic patients [41]. Also, previous research has reported a synergic relationship between physical symptom burden and mental health [46]. Our finding suggests the need for support for clinicians to consider the potential impact of post-Ebola physical symptom burden on EVD survivors' mental wellbeing.

Previous research has reported that individuals with more chronic physical health symptoms are more likely to have limited physical activities leading to less social interaction, and these factors are linked to low quality of life [47]. Consistent with finding from a HRQoL study among patients with chronic disease [41], EVD survivors in our study were more likely to report decreased physical and mental health as the level of stigmatisation from the public increases. Our finding suggests that family and community stigmatisation, ostracisation and discrimination negatively affected EVD survivors' physical and mental health. The association between enacted stigma and mental health in our study suggests that EVD survivors may start to experience feelings of shame, guilt, worthlessness, poor self-esteem and suicidal thoughts due to being are ostracised and rejected by the public, leading to poor mental health. Similar findings have been reported among HIV/AIDS patients, in which internalised stigma was related to lower emotional wellbeing [48]. Our finding may be explained in that stigma has been reported to be common among survivors of emerging and re-emerging infectious disease and, it has been reported to be associated with greater psychiatric symptoms, including depression and post-traumatic stress disorder [10, 49]. Community stigmatisation, discrimination and ostracisation affect patient's help- and treatment-seeking behaviours and treatment adherence, thereby putting their health at risk [10, 50-52] and, this might explain our result. Anti-stigma interventions in the form of mental health literacy campaigns (implemented by government or non-governmental organisations) can provide correct 
information about the stigmatised condition aimed at correcting misinformation, dispelling myths, and/or contradicting negative attitudes and beliefs [53]. Also, peer support and interventions that will allow contact between EVD survivors and the public to overcome the existing interpersonal divide and foster positive connection and interaction [53] can be considered by government or non-governmental agencies to help reduce stigma towards EVD survivors and invariably improve their overall wellbeing. Given the link between public stigma and decreased physical and mental health in our study, anti-stigma and discriminatory laws need to be enacted by the government and local authorities at the national and community levels to prevent and protect EVD survivors against community stigmatisation and ostracisation, which will in turn help improve their HRQoL.

Findings from our univariate analysis indicate that the longer the time spent by an EVD survivor as a patient at an Ebola treatment centre was associated with decreased in mental health although there was no statistically significant association in the multivariate analysis. Our finding is in line with a recent study among COVID-19 survivors, in which no significant association existed between mental health component score and length of stay at the COVID-19 treatment centre [19]. Our finding might be due to the traumatic events EVD survivors experience while being admitted at an Ebola treatment centre. These traumatic events include flashbacks associated with witnessing fellow EVD patients dying, the uncertainty around mortality associated with living with EVD and, feelings of loneliness and isolation [6]. A previous study has reported high prevalence mental health related symptoms among EVD patients during their time at ETC [54]. Further research is required to explore the impact length of stay at an Ebola treatment centre has on mental health among EVD survivors and survivors of other emerging infectious disease.

Our study has certain limitations that readers should consider when interpreting the findings. A causeeffect relationship could not be inferred, given that we employed a cross-sectional design in our study. A longitudinal study is required going forward to determine whether HRQoL improves with time given that our study employed a cross-sectional design. A future study should compare HRQoL scores with the general population since our study did not compare scores to the HRQoL of the general Sierra Leonean population. There is a tendency for recall bias, given that the data were based on retrospective self-report. Our study failed to assess EVD survivors' level of social support, which can be a potential cofounder of HRQoL. Also, the non-linear relationship between factors such as age, symptom burden and HRQoL should be further explored in future studies. Notwithstanding these limitations, our findings have relevance to EVD survivors in Sierra Leone since a nationwide sample was used in our study.

\section{Conclusions}

Our study has improved our understanding of how socio-demographic, health related, and psycho-social (Ebola-related stigma) factors might influence the HRQoL of EVD survivors in Sierra Leone. Role limitation-physical, and role limitation-emotional were the most affected domains suggesting that EVD survivors maybe suffering from poor physical and mental health. Age, post-Ebola symptom burden and Ebola-related stigma were associated with decreased levels of physical and mental health of EVD survivors, and these characteristics should be considered by healthcare professionals, including mental health providers as possible risk factors for EVD survivors' HRQoL. These findings emphasised the need for EVD survivors to access comprehensive healthcare that includes specialist care and mental health services. Also, community-driven stigma reduction strategies such as psychoeducation, cognitive techniques, peer support, legislative and policy change at the local and national level all need to be explored to improve EVD survivors' HRQoL.

\section{Abbreviations \\ EVD: Ebola virus disease; ETC: Ebola treatment centre; HRQoL: Health related quality of life.}

\section{Acknowledgements}

We want to express our thanks and appreciation to the Ebola survivors who agreed to participate in this study. We also want to extend our appreciation to the staff of the Sierra Leone Ebola survivors association as well as all data collectors for their support during data collection. We want to extend our appreciation to the dean of the faculty of pharmaceutical sciences, College of Medicine and Allied Health Sciences, University of Sierra Leone.

\section{Authors' contributions}

PBJ conceived of the study, design, collected and analysed the data, wrote the manuscript. JW, AS and JA contributed to study design supervised data collection and reviewed the manuscript. RMG, JAK contributed to study design and manuscript writing. $A B J, M L$ and EBC contributed to study design, data collection and review of the manuscript. All authors approved the final version of the manuscript.

\section{Funding}

The authors have not declared a specific grant for this research from any funding agency in the public, commercial or not-for-profit sectors.

\section{Availability of data and materials}

Due to confidentiality and privacy concerns, and given the sensitivity surrounding stigma and discrimination among Ebola survivors, our study did not receive approval from the Sierra Leone Ethics and Scientific Review

Committee to publicly share the raw data. Also, Ebola survivors consented to participate in the study on the basis that their data would not be shared with anyone except members of the research team. However, upon reasonable 
request, the anonymised raw data underlying the findings of this study can be made available through the corresponding Author.

\section{Declarations}

\section{Ethics approval and consent to participate}

We obtained ethics approval to conduct the study from the Sierra Leone Ethics and Scientific Review Committee. EVD survivors were informed about the scope and nature of the study as well as the freedom to opt at any time. Written consent to participate in the study was obtained from each survivor before being interviewed. Consent to participate in the study was interpreted by signing or thumb printing (for illiterate participants) the consent form.

\section{Consent for publication}

Not applicable.

\section{Competing interests}

The authors declared no conflict of interest.

\section{Author details}

${ }^{1}$ National Centre for Naturopathic Medicine, Faculty of Health, Southern Cross University, Lismore, NSW 2480, Australia. ${ }^{2}$ Faculty of Pharmaceutical Sciences, College of Medicine and Allied Health Sciences, University of Sierra Leone, Freetown, Sierra Leone. ${ }^{3}$ African Population and Health Research Center (APHRC), Nairobi, Kenya. ${ }^{4}$ Australian Research Centre in Complementary and Integrative Medicine, Faculty of Health, University of Technology Sydney, Ultimo, Sydney, NSW 2007, Australia. ${ }^{5}$ Department of Pharmacy Administration and Clinical Pharmacy, School of Pharmacy, Xi'an Jiaotong University, \#76 Yanta West Road, Xi'an 710061, China. ${ }^{6}$ Faculty of Basic Medical Sciences College of Medicine and Allied Health Sciences, University of Sierra Leone, Freetown, Sierra Leone. ${ }^{7}$ Institute for Global Health and Development, Queen Margaret University Edinburg, Musselburgh, Scotland, UK.

Received: 24 September 2021 Accepted: 4 January 2022

Published online: 15 January 2022

\section{References}

1. WHO. Ebola virus disease. Key facts. 2019. https://www.who.int/newsroom/fact-sheets/detail/ebola-virus-disease. Accessed 14 October 2019

2. WHO. Ebola-democratic republic of the Congo. 2021. https://www.who int/emergencies/disease-outbreak-news/item/2021-DON325. Accessed 4th June 2021.

3. WHO. Ebola virus disease-democratic Republic of the Congo. 2019 https://www.who.int/csr/don/06-june-2019-ebola-drc/en/. Accessed 8 July 2019.

4. WHO. Ebola situation report-30 March 2016. 2016. http://apps.who.int/ ebola/current-situation/ebola-situation-report-30-march-2016. Accessed 16 October 2017

5. WHO. Ebola situation report-15 April 2015. 2015, https://apps.who.int/ ebola/current-situation/ebola-situation-report-15-april-2015. Accessed 12 June 2019

6. James P, Wardle J, Steel A, Adams J. Post-Ebola psycho-social experiences and coping mechanisms among Ebola survivors: a systematic review. Trop Med Int Health. 2019;24:671-91.

7. Vetter P, Kaiser L, Schibler M, Ciglenecki I, Bausch DG. Sequelae of Ebola virus disease: the emergency within the emergency. Lancet Infect Dis. 2016;16:e82-91.

8. Sierra Leone Association of Ebola Survivors-Our Membership. https:// www.slaes.org/home.html.

9. Jagadesh S, Sevalie S, Fatoma R, Sesay F, Sahr F, Faragher B, Semple MG, Fletcher TE, Weigel R, Scott JT. Disability among Ebola survivors and their close contacts in Sierra Leone: a retrospective case-controlled cohort study. Clin Infect Dis. 2018;66:131-3.

10. James PB, Wardle J, Steel A, Adams J. An assessment of Ebola-related stigma and its association with informal healthcare utilisation among Ebola survivors in Sierra Leone: a cross-sectional study. BMC Public Health. 2020;20:182.
11. Bah AJ, James PB, Bah N, Sesay AB, Sevalie S, Kanu JS. Prevalence of anxiety, depression and post-traumatic stress disorder among Ebola survivors in northern Sierra Leone: a cross-sectional study. BMC Public Health. 2020;20:1391.

12. Bond NG, Grant DS, Himmelfarb ST, Engel EJ, Al-Hasan F, Gbakie M, Kamara F, Kanneh L, Mustapha I, Okoli A, et al. Post-Ebola syndrome presents with multiple overlapping symptom clusters: evidence from an ongoing cohort study in Eastern Sierra Leone. Clin Infect Dis. 2021;73:1046-54

13. Karimi M, Brazier J. Health, health-related quality of life, and quality of life: What is the difference? Pharmacoeconomics. 2016;34:645-9.

14. Hui D, Joynt G, Wong K, Gomersall C, Li T, Antonio G, Ko F, Chan M, Chan D, Tong M. Impact of severe acute respiratory syndrome (SARS) on pulmonary function, functional capacity and quality of life in a cohort of survivors. Thorax. 2005;60:401-9.

15. Talman S, Boonman-de Winter L, de Mol M, Hoefman E, van Etten R, De Backer I. Pulmonary function and health-related quality of life after COVID-19 pneumonia. Respir Med. 2021;176:106272.

16. Mafirakureva N, Dzingirai B, Postma MJ, van Hulst M, Khoza S. Healthrelated quality of life in HIV/AIDS patients on antiretroviral therapy at a tertiary care facility in Zimbabwe. AIDS Care. 2016;28:904-12.

17. Batawi S, Tarazan N, Al-Raddadi R, Al Qasim E, Sindi A, Johni SA, AlHameed FM, Arabi YM, Uyeki TM, Alraddadi BM. Quality of life reported by survivors after hospitalization for Middle East respiratory syndrome (MERS). Health Qual Life Outcomes. 2019;17:1-7.

18. Kwek S-K, Chew W-M, Ong K-C, Ng AW-K, Lee LS-U, Kaw G, Leow MK-S. Quality of life and psychological status in survivors of severe acute respiratory syndrome at 3 months postdischarge. J Psychosom Res. 2006;60:513-9.

19. Chen K-Y, Li T, Gong F-H, Zhang J-S, Li X-K. Predictors of health-related quality of life and influencing factors for COVID-19 patients, a follow-up at one month. Front Psychiatry. 2020. https://doi.org/10.3389/fpsyt.2020. 00668.

20. Gamberini L, Mazzoli CA, Sintonen H, Colombo D, Scaramuzzo G, Allegri D, Tonetti T, Zani G, Capozzi C, Giampalma E, et al. Quality of life of COVID19 critically ill survivors after ICU discharge: 90 days follow-up. Qual Life Res Int J Qual Life Asp Treat Care Rehabil. 2021;30:1-13.

21. Karafillakis E, Jalloh MF, Nuriddin A, Larson HJ, Whitworth J, Lees S, Hageman KM, Sengeh P, Jalloh MB, Bunnell R, et al. "Once there is life, there is hope" Ebola survivors' experiences, behaviours and attitudes in Sierra Leone, 2015. BMJ Glob Health. 2016;1:e000108.

22. Delamou A, Camara BS, Kolie JP, Guemou AD, Haba NY, Marquez S, Beavogui AH, Delvaux T, Griensven J, van Griensven J. Profile and reintegration experience of Ebola survivors in Guinea: a cross-sectional study. Trop Med Int Health. 2017;22:254-60

23. Lotsch F, Schnyder J, Goorhuis A, Grobusch MP. Neuropsychological long-term sequelae of Ebola virus disease survivors - a systematic review. Travel Med Infect Dis. 2017;18:18-23.

24. WHO. Clinical care for survivors of Ebola virus disease. Interim Guidance 2016. http://apps.who.int/iris/bitstream/10665/204235/1/WHO_EVD_ OHE_PED_16.1_eng.pdf?ua=1.

25. Degroote $S$, Vogelaers D, Vandijck DM. What determines health-related quality of life among people living with HIV: an updated review of the literature. Arch Public Health. 2014;72:40.

26. Ferrans CE, Zerwic JJ, Wilbur JE, Larson JL. Conceptual model of healthrelated quality of life. J Nurs Scholarsh. 2005;37:336-42.

27. Wilson IB, Cleary PD. Linking clinical variables with health-related quality of life: a conceptual model of patient outcomes. JAMA. 1995;273:59-65.

28. Ebola maps. Maps from 30 March 2016. Geographical distribution of new and total confirmed cases in Guinea, Liberia, and Sierra Leone. http:// apps.who.int/ebola/sites/default/files/thumbnails/image/sitrep_casec ount_40.png?ua $=1$.

29. Holzemer WL, Uys LR, Chirwa ML, Greeff M, Makoae LN, Kohi TW, Dlamini PS, Stewart AL, Mullan J, Phetlhu RD, et al. Validation of the HIV/AIDS Stigma Instrument—PLWA (HASI-P). AIDS Care. 2007;19:1002-12.

30. Davtyan M, Brown B, Folayan MO. Addressing Ebola-related stigma: lessons learned from HIV/AIDS. Glob Health Action. 2014;7:26058.

31. Wagner A, Wyss K, Gandek B, Kilima P, Lorenz S, Whiting D. A Kiswahili version of the SF-36 Health Survey for use in Tanzania: translation and tests of scaling assumptions. Qual Life Res. 1999:8:101-10. 
32. Patel AR, Lester RT, Marra CA, van der Kop ML, Ritvo P, Engel L, Karanja S, Lynd LD. The validity of the SF-12 and SF-6D instruments in people living with HIV/AIDS in Kenya. Health Qual Life Outcomes. 2017;15:143.

33. Anyayo L, Ashaba S, Kaggwa MM, Maling S, Nakimuli-Mpungu E. Healthrelated quality of life among patients with bipolar disorder in rural southwestern Uganda: a hospital based cross sectional study. Health Qual Life Outcomes. 2021;19:84.

34. Kisaka SM, Rutebemberwa E, Kasasa S, Ocen F, Nankya-Mutyoba J. Does health-related quality of life among adults with pulmonary tuberculosis improve across the treatment period? A hospital-based cross sectional study in Mbale Region, Eastern Uganda. BMC Res Notes. 2016;9:1-10.

35. RAND. 36-Item short form survey (SF-36) scoring instructions. 2021. https://www.rand.org/health-care/surveys_tools/mos/36-item-shortform/scoring.html Accessed 8th June 2021.

36. Farivar SS, Cunningham WE, Hays RD. Correlated physical and mental health summary scores for the SF-36 and SF-12 Health Survey, V. 1. Health Qual Life Outcomes. 2007;5:1-8.

37. Ware JE, Keller SD, Kosinski M. SF-36 physical and mental health summary scales. Boston: Health Assessment Lab Boston; 1994.

38. Secor A, Macauley R, Stan L, Kagone M, Sidikiba S, Sow S, Aronovich D, Litvin K, Davis N, Alva S, Sanderson J. Mental health among Ebola survivors in Liberia, Sierra Leone and Guinea: results from a cross-sectional study. BMJ Open. 2020;10:e035217.

39. James PB, Wardle J, Steel A, Adams J. Ebola survivors' healthcare-seeking experiences and preferences of conventional, complementary and traditional medicine use: a qualitative exploratory study in Sierra Leone. Complement Ther Clin Pract. 2020;39:101127.

40. James PB, Wardle J, Steel A, Adams J, Bah AJ, Sevalie S. Providing healthcare to Ebola survivors: a qualitative exploratory investigation of healthcare providers' views and experiences in Sierra Leone. Glob Public Health. 2020;15:1-16

41. Feyisa BR, Yilma MT, Tolessa BE. Predictors of health-related quality of life among patients with diabetes on follow-up at Nekemte specialised Hospital, Western Ethiopia: a cross-sectional study. BMJ Open. 2020;10:e036106-e036106.

42. Goli M, Salarvand S, Dehvan F, Ghafouri H, Dalvand S, Gheshlagh RG, Vahedian-azimi A. Health-related quality of life in Iranian patients with Thalassemia major: a systematic review and meta-analysis. Int J Pediatr Mashhad. 2018;6:8483-94.

43. Abdulla A, Adams N, Bone M, Elliott AM, Gaffin J, Jones D, Knaggs R, Martin D, Sampson L, Schofield P. Guidance on the management of pain in older people. Age Ageing. 2013;42:11-57.

44. Ruoff GE. Challenges of managing chronic pain in the elderly. In: Seminars in arthritis and rheumatism. Elsevier; 2002, pp. 43-50.

45. Zemed A, Nigussie Chala K, Azeze Eriku G, Yalew Aschalew A. Healthrelated quality of life and associated factors among patients with stroke at tertiary level hospitals in Ethiopia. PLoS ONE. 2021;16:e0248481.

46. Fitzgerald P, Lo C, Li M, Gagliese L, Zimmermann C, Rodin G. The relationship between depression and physical symptom burden in advanced cancer. BMJ Support Palliat Care. 2015;5:381.

47. Anokye NK, Trueman P, Green C, Pavey TG, Taylor RS. Physical activity and health related quality of life. BMC Public Health. 2012;12:624.

48. Parcesepe A, Tymejczyk O, Remien R, Gadisa T, Kulkarni SG, Hoffman S, Melaku Z, Elul B, Nash D. HIV-related stigma, social support, and psychological distress among individuals initiating ART in Ethiopia. AIDS Behav. 2018;22:3815-25.

49. Saeed F, Mihan R, Mousavi SZ, Reniers RL, Bateni FS, Alikhani R, Mousavi SB. A narrative review of stigma related to infectious disease outbreaks: What can be learned in the face of the Covid-19 pandemic? Front Psychiatry. 2020. https://doi.org/10.3389/fpsyt.2020.565919.

50. Rueda S, Mitra S, Chen S, Gogolishvili D, Globerman J, Chambers L, Wilson M, Logie CH, Shi Q, Morassaei S, Rourke SB. Examining the associations between HIV-related stigma and health outcomes in people living with HIV/AIDS: a series of meta-analyses. BMJ Open. 2016;6:e011453.

51. Kane JC, Elafros MA, Murray SM, Mitchell EMH, Augustinavicius JL, Causevic S, Baral SD. A scoping review of health-related stigma outcomes for high-burden diseases in low- and middle-income countries. BMC Med. 2019:17:17.

52. Katz IT, Ryu AE, Onuegbu AG, Psaros C, Weiser SD, Bangsberg DR, Tsai AC. Impact of HIV-related stigma on treatment adherence: systematic review and meta-synthesis. J Int AIDS Soc. 2013;16:18640-18640.
53. National Academies of Sciences E, Medicine. Ending discrimination against people with mental and substance use disorders: the evidence for stigma change. Washington: National Academies Press; 2016.

54. Weissbecker I, Roshania R, Cavallera V, Mallow M, Leichner A, Antigua J, Gao J, Levine A. Integrating psycho-social support at Ebola treatment units in Sierra Leone and Liberia. Intervention. 2018;16:69-78.

\section{Publisher's Note}

Springer Nature remains neutral with regard to jurisdictional claims in published maps and institutional affiliations.
Ready to submit your research? Choose BMC and benefit from:

- fast, convenient online submission

- thorough peer review by experienced researchers in your field

- rapid publication on acceptance

- support for research data, including large and complex data types

- gold Open Access which fosters wider collaboration and increased citations

- maximum visibility for your research: over $100 \mathrm{M}$ website views per year

At BMC, research is always in progress.

Learn more biomedcentral.com/submissions 